\title{
ÍNDICES DE SUSTENTABILIDADE DE PROJETOS DA ECONOMIA SOLIDÁRIA: O CASO ESPERANÇA/COOPESPERANÇA
}

\author{
Marta Von Ende \\ Mestre em Administração pela Universidade Federal do Rio Grande do Sul- UFRGS \\ martavonende@yahoo.com.br \\ Gabriel Murad Velloso Ferreira \\ Doutorando em Extensão Rural pela Universidade Federal de Santa Maria - UFSM \\ Professor da Universidade Federal de Santa Maria - UFSM \\ gabriel@politecnico.ufsm.br \\ Gustavo Fontinelli Rossés \\ Doutorando em Extensão Rural pela Universidade Federal de Santa Maria - UFSM \\ Professor da Universidade Federal de Santa Maria - UFSM \\ gustavo@politecnico.ufsm.br \\ Jaime Peixoto Stecca \\ Doutorando em Administração pela Universidade de São Paulo - USP \\ Professor da Universidade Federal de Santa Maria \\ jaime@ufsm.br \\ Lúcia Rejane da Rosa Gama Madruga \\ Doutora em Agronegócios pela Universidade Federal do Rio Grande do Sul - UFRGS \\ Professora da Universidade Federal de Santa Maria \\ lucia.rejane@hotmail.com
}

\author{
Aline Barasuol \\ Graduada em Gestão de Cooperativas pela Universidade Federal de Santa Maria - UFSM \\ alynebarasuol@yahoo.com.br
}

\section{RESUMO}

A discussão sobre a aplicação do conceito de sustentabilidade tem ampliado as pesquisas na área. Neste âmbito, destaca-se a realização de estudos para a avaliação da sustentabilidade ambiental, social e econômica de sistemas produtivos. No meio rural, por exemplo, as cooperativas sociais têm se mostrado uma alternativa eficaz para o desenvolvimento sustentável da agropecuária brasileira. Nesse contexto, o Projeto Esperança/Cooesperança se alicerça e busca desenvolver a agricultura familiar da região central do Rio Grande do Sul. Por isso, este trabalho tem como objetivo identificar os níveis de sustentabilidade econômica, ambiental e social dos produtores rurais agropecuários participantes do Projeto Esperança/Cooesperança. Para isto, este estudo foi realizado com base em dados primários, obtidos por meio da aplicação de questionários semiestruturados junto a quinze produtores rurais do setor de hortifrutigranjeiros associados ao Projeto. Estes dados possibilitaram a elaboração de índices para as dimensões ambiental, social e econômica. Como principais resultados, observou-se que a dimensão Ambiental obteve o melhor desempenho (ISA=0,81), seguida da dimensão Social (ISS=0,58) e Econômica (ISE=0,26). Dessa forma, o índice médio de sustentabilidade foi de 0,48 .

Palavras-chave: Economia solidária; Indicadores; Projeto esperança/cooesperança; Sustentabilidade.

\section{SUSTAINABILITY INDICES OF SOLIDARITY ECONOMY PROJECTS: THE ESPERANÇA/COOPESPERANÇA CASE}

\section{ABSTRACT}

Conceptualization and application has enhanced research in the area of sustainability. We examined sustainability studies to evaluate the environmental, social, and economic sustainability of production systems. In the rural environment, social cooperatives have been an effective alternative for the sustainable development of Brazilian agriculture. The Esperança/Cooesperança Project is grounded in this context and seeks to develop agriculture in the central region of Rio Grande do Sul, Brazil. Therefore, this study aims to identify the levels of economic, environmental, and social sustainability of rural agricultural producers participating in the Esperança/Cooesperança Project. This study was based on primary data obtained through the application of semistructured questionnaires to fifteen farmers from the horticultural sector associated with the Project. These data allowed for the creation of indexes for the environmental, social, and economic sustainability. The main results showed that the environmental dimension had the best performance (ISA $=0.81$ ), followed by the social dimension (ISS $=0.58$ ), and the economic dimension (ISE $=0.26$ ). The sustainability average rate was 0.48 .

Key words:Esperança/cooesperança project; Indexes; Solidarity economy; Sustainability 


\section{INTRODUÇÃO}

A sustentabilidade é um tema que recentemente tem chamado a atenção atenção de parte da população mundial e, até por isso, a preocupação com seu conceito e sua aplicação acarretou em uma nova maneira de se buscar o desenvolvimento. Um marco dessas discussões no Brasil foi a Conferência Mundial sobre o Meio Ambiente (Rio-92) e deu início aos estudos mais profundos a respeito da sustentabilidade.

A comunidade científica tem procurado conceituar e desenvolver o tema sustentabilidade. Cavalcanti (1998) conceitua a sustentabilidade como a possibilidade de se obter continuamente condições iguais ou superiores de vida para um grupo de pessoas e seus sucessores em um ecossistema. Em relação ao conceito original de Desenvolvimento Sustentável (DS), proposto pela Comissão Mundial do Desenvolvimento e Meio Ambiente em 1987, a Comissão Brundtland, está enunciado como "[...]atender às necessidades da geração presente sem comprometer a habilidade das gerações futuras de atenderem suas próprias necessidades" (Amaral; Rovere, 2003). Depontil (2002) afirma que o termo sustentabilidade é originário do latim sustentare e que significa suster, suportar, conservar em bom estado, manter, resistir. Disso, então, elabora o autor que sustentável é tudo aquilo que é capaz de ser suportado, mantido.

Sachs (1990) traz um conceito de sustentabilidade que contempla, entre outras, três dimensões principais, sendo elas: a social, a econômica e a ambiental. A dimensão social busca estabelecer um padrão estável de crescimento, com uma redução das diferenças sociais por meio da melhor distribuição de renda. A sustentabilidade econômica, por sua vez, representa a correta alocação e destinação dos recursos naturais e o fluxo de inversões públicas e privadas constantes. Já a dimensão ambiental, preocupa-se com o uso dos recursos naturais evitando, ao máximo, a deterioração do ambiente (Sachs, 1990).

O conceito de sustentabilidade é de natureza multidisciplinar, de modo que para avaliar a sustentabilidade, deve-se utilizar sempre de um conjunto de indicadores (Marzall; Almeida, 2000). Os indicadores são modos de representação de características e propriedades de uma dada realidade que têm por finalidade buscar a otimização do processo de tomadas de decisão, tendo como parâmetro, a transformação desejada daquela realidade no tempo (Marangon et al., 2004).

Marangon et al. (2004) reforçam que os indicadores diferenciam-se por apresentarem uma visão de integração entre os elementos sociais, ambientais e econômicos, sendo que um bom indicador é aquele capaz de antever possíveis problemas que poderão ocorrer, propondo soluções para tanto.

O ambiente agrícola apresenta características socioeconômicas e físicas que o tornam um espaço significativo para a busca de compreensão sobre o tema sustentabilidade. Segundo Brasil (2006), a estrutura agrária brasileira ainda é concentrada, uma vez que o número de estabelecimentos não-familiares representa $15,6 \%$ e contempla $75,7 \%$ da área ocupada. Apesar de ocupar apenas $24,3 \%$ da área total dos estabelecimentos agropecuários, a agricultura familiar é responsável por $38 \%$ do valor bruto gerado. Destaca-se, ainda, a contribuição dos agricultores familiares na produção de mandioca, feijão, milho e arroz, sendo responsáveis por $87 \%, 70 \%, 46 \%$ e $34 \%$, respectivamente, da produção nacional desses itens. Além disso, geram mais de 12 milhões de empregos diretos, sendo os principais responsáveis pela manutenção do homem no campo (Brasil, 2006).

Contudo, a utilização intensiva de máquinas e produtos químicos responde por inúmeros prejuízos de cunho social e ambiental. Bastos et al. (2008) apontam ainda que os agricultores familiares sofrem problemas referentes à baixa capitalização, dependência de mercados locais e regionais, enfraquecimento do solo e a minufundização.

Mesquita Filho (2006) destaca a crescente busca por um modelo de exploração agrícola que venha a reduzir os prejuízos ao meio ambiente e aos seres humanos, sendo essa questão cada vez mais discutida tanto no meio acadêmico quanto na sociedade em geral, tendo em vista que a falta de equidade social e a degradação ambiental intensificam-se.

Revista de Gestão Social e Ambiental - RGSA, São Paulo, v. 6, n. 3, p. 47-63, set./dez. 2012. 
Ao longo da história da atividade rural brasileira, diversos mecanismos podem ser apontados como mediadores dos problemas e que se inseriram nesse ambiente com a finalidade de diminuir a dispersão e a individualidade e para proporcionar melhores condições de negociação para os pequenos produtores, entre os quais se destacam as cooperativas sociais. Conforme Figueiredo (2009), a cooperativa social insere o associado em uma cadeia de trabalhos relacionada a estudo e formação, proporcionando acesso a informações e a maiores conhecimentos sobre as práticas realizadas.

No contexto onde se inserem as cooperativas sociais e outros mecanismos de organização social que não visam lucro, acrescenta-se a Economia Solidária que, conforme Candeias, Macdonald e Mello (2005), é composta por uma gestão coletiva exercida por seus trabalhadores, em que eles são os responsáveis pelo controle, gerenciamento e a administração do capital. Tal gestão visa os princípios de repartição equitativa dos resultados e a própria valorização do trabalho dos seus membros.

A lógica da Economia Solidária é a procura pela satisfação das necessidades e não apenas o acumular dos lucros, de modo que um de seus requisitos é a educação, a capacitação e a geração de informações para os sócios. Outra característica relevante da Economia Solidária é o movimento social formado por seus membros, que tratam das atividades que, simultaneamente, articulam a respeito da luta política e da geração de renda. A Economia Solidária tem como uma de suas preocupações centrais a capacidade de oferecer um comércio justo (Lamge, 2009)

Em Santa Maria - RS, o Projeto Esperança/Cooesperança se alicerça nos pressupostos da Economia Solidária e busca desenvolver a agricultura familiar na região. O referido Projeto conta com o envolvimento de pequenos agricultores, cooperados, que realizam diversas ações para desenvolver a atividade, a fim de originar uma maior sustentabilidade (econômica, social e ambiental). Armazéns, terminais de comércio, produção de artesanatos, feiras, ações sociais, educação ambiental e práticas agroecológicas, entre outros, são exemplos de ações concretas do Projeto (Icaza; Freitas, 2006).

Inserida nesse contexto, esta pesquisa tem como objetivo identificar os níveis de sustentabilidade econômica, ambiental e social dos produtores rurais agropecuários participantes do Projeto Esperança/Cooesperança. Espera-se, com isso, buscar elementos para propor e estimular ações coletivas que possam contribuir para o desenvolvimento sustentável dos produtores rurais envolvidos no projeto.

É importante salientar que o caso estudado foi escolhido em razão de o projeto estar vinculado à Economia Solidária, que possui um forte viés para as práticas agroecológias. O caso em análise é reconhecido na região pela comercialização de produtos mais limpos, o que, a princípio, reflete na adoção de práticas mais sustentáveis. Isto motivou a realização da pesquisa, para que fosse possível identificar concretamente não apenas o nível de sustentabilidade ambiental, mas também o social e o econômico, que são essenciais para o entendimento da sustentabilidade do sistema como um todo.

Este trabalho pretende, portanto, contribuir com as discussões acerca do desenvolvimento sustentável em uma rede de cooperados, ressaltando a importância e a relevância social dessa questão, em face das complexidades que envolvem.

\section{SUSTENTABILIDADE E A PRODUÇÃO AGROPECUÁRIA}

As discussões sobre o conceito de sustentabilidade se iniciam em resposta à preocupação frente ao intenso desenvolvimento econômico vivido pelos países, uma vez que o meio ambiente não suportaria por muito tempo o crescimento humano e o consumo (Lourenço, 2006). Diante deste cenário, pesquisadores passaram a buscar um novo modelo de desenvolvimento que garantisse o bem-estar das futuras gerações, surgindo então a noção de sustentabilidade que, segundo Moisés (1999), está associada à estabilidade, permanência no tempo e durabilidade. Essa ideia foi proposta no início da década de 1970, em estudos de cunho ecológico, que focalizavam a interdependência

Revista de Gestão Social e Ambiental - RGSA, São Paulo, v. 6, n. 3, p. 47-63, set./dez. 2012. 
entre uma população e os recursos de seu ambiente. No entanto, nos anos 1980, se estendeu sua abrangência para abarcar as relações entre desenvolvimento e meio ambiente, no processo de preparação da Conferência da Organização das Nações Unidas (ONU) que ocorreu no Rio de Janeiro, em 1992

Mesquita Filho (2006) destaca que o "Relatório Brundtland" ou "Nosso Futuro Comum", elaborado pela Comissão Mundial sobre Meio Ambiente e Desenvolvimento, apresenta a definição oficial do conceito de desenvolvimento sustentável: "[...]aquele que satisfaz as necessidades do presente sem comprometer a capacidade das gerações futuras de satisfazerem as suas próprias necessidades". Nesse documento, também está explicitada a ideia de um desenvolvimento contínuo, sem exaurir os recursos naturais.

O "Relatório Brundtland", segundo Benvindo (2009), tem como ideia central formular os princípios do desenvolvimento sustentável e, em sua essência, é um processo de transformação no qual as respostas à direção de investimentos, à orientação do desenvolvimento tecnológico e à mudança institucional, com o objetivo de alcançar a harmonia e vem reforçar o potencial do presente e do futuro, para atender as necessidades básicas e as aspirações humanas.

Para esse mesmo autor, o documento indica a eliminação da pobreza em massa como pré-requisito necessário para um desenvolvimento que alie crescimento e preservação dos recursos naturais. Da mesma forma, para que a sustentabilidade seja alcançada, segundo Pollmann (2008), é preciso planejamento e reconhecimento de que os recursos naturais são finitos, ou seja, a sustentabilidade representa uma nova forma de desenvolvimento econômico, que leva em conta o meio ambiente sem a exaustão dos recursos naturais. A sustentabilidade é determinada por um conjunto de fatores (econômicos, sociais, ambientais, entre outros) (Marzall; Almeida, 2000).

Ante tal cenário, é crescente a busca de um modelo de exploração agropecuária que venha a reduzir os prejuízos ao meio ambiente e aos seres humanos. Assim, segundo Mesquita Filho (2006), a agricultura sustentável surge, nesse contexto, como uma alternativa viável ao modelo de exploração agrícola convencional. Aliglieri, Aliglieri e Kruglianskas (2009) atestam ser o agronegócio um dos principais responsáveis pelas fragilidades ambientais. Segundo os autores, algumas práticas, tais como fertilização química do solo, controle químico de pragas, monocultura, desmatamento e queimadas são corriqueiras e recorrentes. As queimadas e o desmatamento são as maiores responsáveis pelo Brasil ocupar o quarto lugar em emissão de dióxido de carbono no mundo. Souza (2004) ressalta o rompimento da agricultura sustentável com a noção de desenvolvimento agrícola associado, principalmente, ao aumento da produtividade. Seu objetivo maior é a manutenção da produtividade agrícola com o mínimo possível de impactos ambientais e com retornos econômico-financeiros adequados à meta de redução da pobreza, atendendo assim às necessidades sociais das populações rurais.

Leff $(2004$, p.62) argumenta que "[...]os conflitos socioambientais emergem de princípios éticos, direitos culturais e lutas pela apropriação da natureza que vão além da internalização dos custos ecológicos para assegurar um crescimento sustentado". Para Almeida (1997), os conceitos de desenvolvimento agrícola sustentável incorporam, de um modo geral, as preocupações de integrar a produtividade dos sistemas agrícolas aos aspectos econômicos, sociais e ambientais.

A análise do DS de uma determinada produção precisa, portanto, levar em conta pelo menos os fatores de ordem econômica, social e ambiental, procurando conciliar o desenvolvimento do meio econômico e social, mas respeitando sempre o meio-ambiente.

Desai (2005) ressalta que o desenvolvimento sustentável vem emergindo como um novo paradigma de desenvolvimento, integrando crescimento econômico, desenvolvimento social e proteção ambiental como elementos de desenvolvimento de longo prazo interdependentes e que se suportam mutuamente. Para o caso específico da agropecuária, deve-se levar em conta que a produção deve ser rentável economicamente, a fim de que possa cobrir os custos da produção e manutenção do núcleo produtor; deve atender e propiciar condições para o alcance das necessidades básicas do indivíduo e o exercício de seus direitos e deve, ainda, ser ecologicamente correta, para não agredir o meio ambiente.

Revista de Gestão Social e Ambiental - RGSA, São Paulo, v. 6, n. 3, p. 47-63, set./dez. 2012. 
Para Hoff (2008), a sustentabilidade econômica cobre a expectativa por um crescimento econômico forte e durável que preserve a estabilidade financeira, em um ambiente no qual a inflação seja baixa e estável e que crie condições para investir e renovar. A sustentabilidade ambiental foca a integridade, produtividade e plasticidade (qualidade das matérias que podem ser moldadas) dos ambientes biológicos e físicos, bem como a preservação de um ambiente saudável. Sobre a sustentabilidade social, enfatiza a importância de alto nível de emprego, de redes de segurança, equidade e de participação democrática nos processos de decisão. O DS estabelece a relação entre as três dimensões e sua complementaridade, a partir das ligações e interações entre as três dimensões. Portanto, as dimensões não devem ser analisadas separadamente, mas sim deve haver conexão e interação entre elas, uma vez que os investimentos para a preservação florestal ou ambiental, por exemplo, alteram a dimensão econômica da produção (Hoff, 2008).

Sachs (1990) considera que a sustentabilidade tem como base cinco dimensões principais que são: social, cultural, ecológica, ambiental e econômica. Bicalho (1998) trabalha com três indicadores para a operacionalização do desenvolvimento sustentável: a equidade, a capacidade e a sustentabilidade. Apesar de existirem diferentes terminologias para a composição dos indicadores de sustentabilidade, verifica-se que todas estão relacionadas, de forma geral, com os fatores de ordem econômica, social e ambiental.

De acordo com Mitchell (1996), um indicador é uma ferramenta que permite a obtenção de informações sobre uma dada realidade, tendo como principal característica a de poder sintetizar um conjunto complexo de informações, retendo apenas o significado essencial dos aspectos analisados, podendo ser visto ainda como uma resposta sintomática às atividades exercidas pelo ser humano em um determinado sistema.

Lourenço (2006) argumenta que os indicadores de sustentabilidade auxiliam os tomadores de decisões a avaliar os resultados práticos das ações públicas para a sustentabilidade. Baseados nos resultados apontados pelos indicadores, os atores públicos planejam estratégias que favoreçam a melhora nas condições de vida do cidadão e a sustentabilidade do sistema. São medidas compostas de variáveis, ou seja, medições baseadas em mais de um dado (Lourenço, 2006).

Um aspecto determinante é a impossibilidade de determinar a sustentabilidade de um sistema considerando apenas um indicador ou indicadores que se refiram a apenas um aspecto do sistema, sendo, portanto, necessário considerar os fatores econômicos, sociais e ambientais (Bouni, 1996; Marzall; Almeida, 2000).

As contribuições teóricas acerca do tema evidenciam a importância das dimensões econômica, social e ambiental em qualquer processo que procure realizar a leitura de uma dada realidade, a partir desse pressuposto teórico. Assim, este trabalho fez uso de tais dimensões para analisar a sustentabilidade de produtores ligados a um projeto de cunho cooperativo.

\section{MÉTODO DE PESQUISA}

Este estudo foi realizado com base em dados primários, obtidos por meio da aplicação de questionários semiestruturados junto a quinze produtores rurais do setor de hortifrutigranjeiros associados ao Projeto Esperança/Cooesperança.

As entrevistas semiestruturadas foram realizadas pela equipe de pesquisa diretamente na feira (feirão colonial) aos sábados, durante quatro semanas, nos meses de setembro e outubro de 2010, sendo que cada entrevista durou, em média, uma hora e consistiu na fonte de informação utilizada para a determinação dos índices de sustentabilidade.

A fim de identificar os níveis de sustentabilidade Econômica, Ambiental e Social dos produtores que participaram desta pesquisa, foram calculados índices para cada um dos aspectos avaliados, econômico, ambiental e social, conforme metodologia apresentada a seguir. As variáveis pesquisadas foram definidas a partir de revisão de literatura, que foi confrontada e complementada com a opinião de especialistas (professores doutores com atuação nas áreas). Destaca-se, ainda, que

Revista de Gestão Social e Ambiental - RGSA, São Paulo, v. 6, n. 3, p. 47-63, set./dez. 2012. 
também foi determinado um Índice de Sustentabilidade (IS) geral, contemplando as três dimensões de sustentabilidade abordadas neste estudo.

\subsection{Operacionalização do Índice de Sustentabilidade Econômica - ISE}

A exemplo do estudo de Mesquita Filho (2006), o lucro obtido pelo produtor foi utilizado como única variável para determinar o índice de sustentabilidade econômica (ISE). O lucro ( $L$ ) foi determinado subtraindo-se as despesas $(D)$ das receitas $(R)$, conforme equação 1 . Destaca-se que, assim como na pesquisa de Oliveira et al. (2008), foram consideradas medidas de resultado econômico agrícola e não-agrícola. Assim, para a determinação da receita total do produtor, foi utilizada a renda anual da família, considerando a renda agrícola e a renda não-agrícola. Da mesma forma, se determinou as despesas.

$$
L=R-D
$$

O indicador de desempenho econômico de cada produtor, dado pelo lucro, foi padronizado, utilizando a equação 2 , a fim de que assumisse um valor entre 0 e 1 .

$$
I D E_{j}=\frac{L_{j}-L_{\min }}{L_{\max }-L_{\min }}
$$

Onde:

$I D E_{j}=$ Indicador de desempenho econômico do produtor $j$

$L_{j}=$ Valor do lucro obtido pelo produtor $j$

$L_{\min }=$ Valor mínimo do lucro no grupo de produtores

$L_{\max }=$ Valor máximo do lucro no grupo de produtores

O ISE foi determinado pela média aritmética dos IDEj obtidos, conforme a equação 3.

$$
I S E=\frac{1}{n} \sum_{j=1}^{n} I D E_{j}
$$

\subsection{Operacionalização do Índice de Sustentabilidade Ambiental - ISA}

O cálculo do índice de sustentabilidade ambiental (ISA) foi realizado a partir das respostas dadas às 18 questões do questionário aplicado que buscam capturar como o produtor lida com o aspecto ambiental em sua propriedade.

Foi atribuído valor 0 ou 1 para cada questão. Se a prática adotada contribui para a sustentabilidade ambiental, foi atribuído o valor 1, caso contrário assumiu-se o valor zero. A figura 1 apresenta as questões e os respectivos escores.

\begin{tabular}{|c|c|c|}
\hline Questão & Resposta & Escore \\
\hline É realizada rotação de culturas no plantio? & \\
Utiliza adubação verde? & \\
Utiliza adubação orgânica? & Sim \\
Utiliza semente selecionada? & Não & 1 \\
Realiza controle de invasoras com práticas orgânicas? & \\
Utiliza consórcio de culturas? & \\
Realiza uso de irrigação? & \\
Existe área de preservação de mato nativo na propriedade? & \\
Realiza controle natural de pragas e doenças? & \\
Utiliza práticas de conservação do solo? & \\
Faz reaproveitamento de resíduos orgânicos? & Sim \\
Realiza reciclagem de resíduos e/ou separação do lixo? & \\
Realiza práticas que auxiliam na preservação da água? & \\
Utiliza algum tipo de assessoria técnica na área ambiental? & \\
\hline Utiliza queimadas? &
\end{tabular}

Revista de Gestão Social e Ambiental - RGSA, São Paulo, v. 6, n. 3, p. 47-63, set./dez. 2012. 


\begin{tabular}{c|c|c|} 
Utiliza fertilizantes químicos? & Não & 1 \\
Faz derrubada de mato nativo para fins de plantio? & &
\end{tabular}

Figura 1 - Escores do índice de sustentabilidade ambiental

Fonte: Adaptado de Mesquita Filho (2006) e Oliveira et al. (2008)

Num primeiro momento, foi determinado o índice de sustentabilidade ambiental por produtor por meio do somatório dos escores atribuídos em cada um dos indicadores das dezoito questões levantadas, conforme equação a seguir.

$$
I S A_{j}=\sum_{i=1}^{18} X_{i j}
$$

Onde:

$I S A_{j}=$ Índice de sustentabilidade ambiental do produtor $j$

$X_{i j}=$ Escore atribuído ao indicador $i$ pelo produtor $j$

Como os escores assumem apenas valor 0 ou 1 em cada questão, o valor absoluto máximo que o ISA pode assumir é 18.

A padronização foi realizada observando a equação 5 a seguir:

$$
I S A_{j P}=\frac{I S A_{j}-I S A_{\text {imin }}}{I S A_{\text {imax }}-I S A_{\text {imin }}}
$$

Onde:

$I S A_{j P}=$ Índice de sustentabilidade ambiental do produtor $j$ padronizado

$I S A_{\text {imin }}=$ Valor mínimo do ISA no grupo de produtores

$I S A_{\text {imax }}=$ Valor máximo do indicador ISA no grupo de produtores

Por fim, o índice de sustentabilidade ambiental geral foi determinado pela média aritmética simples dos índices padronizados.

$$
I S A=\frac{1}{n} \sum_{j=1}^{n} I S A_{j P}
$$

\subsection{Operacionalização do Índice de Sustentabilidade Social - ISS}

O índice de sustentabilidade social (ISS) foi determinado levando em consideração dez questões referentes ao aspecto social. Esse índice contempla aspectos físicos da moradia e questões educacionais.

As questões receberam escores de 0 a 1 , sendo ponderadas de acordo com seu grau de importância, conforme apresentado na figura 2.

$\mathrm{O}$ índice de sustentabilidade social por produtor foi calculado pela equação a seguir:

$$
I S S_{j}=\sum_{i=1}^{10} X_{i j}
$$

Onde:

$I S S_{j}=$ Índice de sustentabilidade social do produtor $j$

$X_{i j}=$ Escore atribuído ao indicador $i$ pelo produtor $j$

Observa-se que o valor máximo do índice de sustentabilidade social que pode ser obtido é 7,74. Isso se deve a atribuição de pesos apresentada na figura 2.

O índice padronizado foi determinado segundo a equação 8: 


$$
I S S_{j P}=\frac{I S S_{j}-I S S_{\text {imin }}}{I S S_{\text {imax }}-I S S_{\text {imin }}}
$$

Onde:

$I S S_{j P}=$ Índice de sustentabilidade social do produtor $j$ padronizado

$I S S_{\text {imin }}=$ Valor mínimo do ISS no grupo de produtores

$I S S_{\text {imax }}=$ Valor máximo do indicador ISS no grupo de produtores

O índice de sustentabilidade social geral representa a média dos índices padronizados.

$$
I S S=\frac{1}{n} \sum_{j=1}^{n} I S S_{j P}
$$

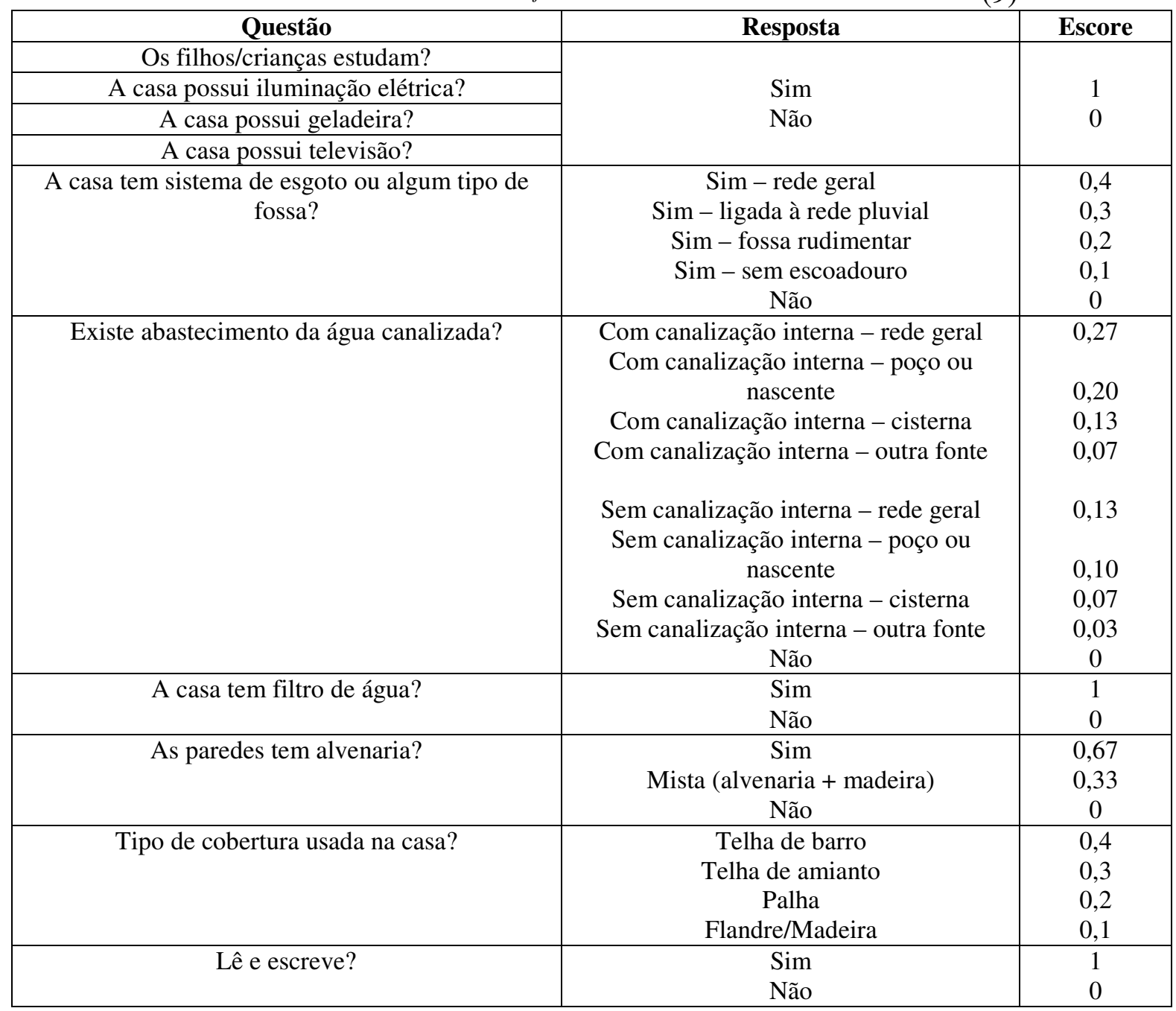

Figura 2 - Escores do índice de sustentabilidade social

Fonte: Adaptado de Mesquita Filho (2006)

Como o objetivo do estudo é determinar não apenas os níveis individuais de sustentabilidade, mas também a sustentabilidade geral da amostra pesquisada, foi calculado um índice de sustentabilidade geral (IS) com base na média dos índices previamente determinados os quais abordam os aspectos econômico, ambiental e social. 


$$
I S=\frac{I S E+I S A+I S S}{3}
$$

A classificação dos índices de sustentabilidade (IS) calculados, da mesma forma que no estudo de Oliveira et al. (2008), teve como referência a utilizada pela ONU (1994) para o Índice de

Desenvolvimento Humano - IDH, de forma que:

Se $0,0<$ IS $\leq 0,5$ indica baixa sustentabilidade.

Se $0,5<$ IS $\leq 0,8$ indica média sustentabilidade.

Se $0,8<$ IS $\leq 1,0$ indica alta sustentabilidade.

\section{APRESENTAÇÃO DOS RESULTADOS}

Esta seção destina-se a análise e discussão dos resultados da pesquisa. Está dividida em três partes. A primeira, refere-se à apresentação do Projeto Esperança/Cooesperança; a segunda, se ocupa de uma caracterização geral dos produtores rurais pesquisados e na terceira, realiza-se o estudo dos indicadores de sustentabilidade.

\subsection{O Projeto Esperança/Cooesperança}

A Cooperativa Mista dos Pequenos Produtores Rurais e Urbanos Vinculados ao Projeto Esperança, Esperança/Cooesperança, foi fundada em 29 de setembro de 1989. É uma central, que, com o Projeto Esperança, reúne e articula os grupos organizados e viabiliza a comercialização direta dos produtos produzidos pelos empreendimentos solidários no campo e na cidade e que fortalecem juntos, a proposta alternativa, solidária, transformadora e autogestionária e do desenvolvimento sustentável (Cooesperança, 2011).

O Projeto Esperança/Cooesperança, conforme Lamge (2009), é uma experiência consolidada e faz parte do trabalho do Banco da Esperança da Arquidiocese de Santa Maria e da Cáritas - RS. Segundo o autor, trata-se de uma forma eficaz e eficiente de fortalecer os grupos, consolidar a articulação e construir Políticas Públicas articuladas em Rede Solidária.

Icaza e Freitas (2006) denotam que os empreendimentos solidários associados ao Projeto Esperança/Cooesperança formam a rede da Teia Esperança, que foi criada no dia 14 de janeiro de 2003. Seu objetivo principal é articular os Empreendimentos Solidários para uma maior união dos produtores e consumidores, motivando o comércio justo, o consumo ético e solidário, por meio dos pontos de comercialização direta dos municípios da região centro e a articulação dos empreendimentos entre si.

Esses mesmos autores destacam, ainda, que são mais de 40 espaços fixos de comercialização direta dos diversos grupos nos municípios da Região Central do Rio Grande do Sul. A Teia Esperança tem como ponto de articulação e integração o terminal de comercialização direta, com troca de experiências e de produtos, todos os sábados no Feirão Colonial Semanal. Nestes pontos, comercializam-se produtos coloniais, hortigranjeiros ecológicos, caseiros, artesanais, panificação, confecção, serigrafia, artesanato em material reciclado, produtos da agroindústria familiar, carne e prestação de serviços, tendo como proposta o cooperativismo, com o intuito de gerar trabalho e renda, dignidade pelo trabalho organizado, enfim, buscando a valorização do trabalho acima do capital, na construção da cidadania e inclusão social.

Vale destacar que esta pesquisa se concentrou em 15 produtores rurais de hortifrutigranjeiros participantes do projeto. Esta delimitação se deu essencialmente por que se pretendia estudar a sustentabilidade ambiental (além da econômica e social), com foco em práticas agroecológicas e, para isto, era necessário pesquisar produtores rurais. Acrescenta-se ainda que não existia nenhum tipo de indicador da sustentabilidade do grupo, apesar de ter sido constatado nas entrevistas que os produtores e a coordenação do projeto percebem que ao longo do tempo houve melhora significativa na qualidade de vida das famílias, como será abordado ao longo do trabalho.

Revista de Gestão Social e Ambiental - RGSA, São Paulo, v. 6, n. 3, p. 47-63, set./dez. 2012. 


\subsection{Caracterização dos produtores rurais}

A maioria dos produtores rurais pesquisados $(60 \%)$ possui sua propriedade rural localizada na cidade de Santa Maria/RS. Dos 40\% restantes, 20\% localizam-se em Silveira Martins e os outros 20\% dividem-se nos municípios de Dona Francisca, Pinhal Grande e Itaara.

Foi possível verificar que 9 produtores (60\% dos entrevistados) possuem a propriedade de dezoito a oitenta e oito anos e os demais possuem de dois a dez anos. Considerando 26 anos, a média que os produtores possuem a propriedade, percebe-se um alto desvio-padrão $(25,74)$, já que existe uma grande disparidade entre os entrevistados. Um produtor possui a propriedade há dois anos enquanto outro possui há oitenta e oito anos.

Referente à situação de posse da terra, percebe-se que $80 \%$ (12) são proprietários e que $20 \%$ (3) não são proprietários, sendo que destes, um produtor não paga nenhum valor pela propriedade e os outros dois pagam um aluguel mensal de $\mathrm{R} \$ 500,00$ por hectare.

Percebeu-se, também, que o tamanho médio das propriedades é de 16 hectares. É importante ressaltar que 53\% dos produtores possuem áreas menores que oito hectares e que $47 \%$ dos produtores possuem uma área acima de 25 hectares, chegando à 50 hectares. Percebe-se, com isso, uma grande variabilidade em relação ao tamanho das propriedades participantes do Projeto Esperança/Cooesperança, pois, enquanto um agricultor possui 1 hectare, o outro possui 50 hectares. Em relação à área agriculturável, percebe-se que os agricultores utilizam, em média, a metade da área da propriedade. Dos quinze agricultores, 67\% possuem uma área de produção menor que sete hectares e $33 \%$ produzem em uma área acima de dez hectares.

Da mesma forma que existem agricultores locatários no projeto, existem também agricultores arrendatários, apresentando-se em pequena parcela. Apenas três agricultores indicaram possuir terra arrendada. A quantidade de hectares arrendados são de 3,5 ha, 5,5 ha e 17 ha.

As principais culturas das propriedades são: mandioca, leite, batata doce, laranja, feijão, milho, alface, frutas, floricultura, massas, soja e arroz. Vale lembrar que os dois produtores que possuem maior área são os que produzem também soja e arroz. Destaca-se, também, que $20 \%$ dos produtores tem como atividade principal a produção de alface.

Sabe-se que o conceito de Economia Solidária está relacionado com a diversificação da produção, no entanto, percebeu-se concentração produtiva em 33,33\% dos produtores (3), que obtêm no mínimo $80 \%$ da renda de um único produto. Desses produtores, dois $(13,33 \%)$ não possuem atividades secundárias, caracterizando-se como monocultura. Um desses produtores trabalha exclusivamente com o cultivo de mudas de flor e o outro com mudas de laranja. Essa é uma questão importante, pois tais produtores não têm nenhuma outra fonte produtiva. A diversificação das culturas é apontada como a maneira mais segura de garantir várias fontes de renda durante o ano agrícola, evitando o risco da perda total da produção por condições adversas. Ressalta-se que o Projeto Esperança/Cooesperança também trabalha no sentido de incentivar a diversificação da matriz produtiva dos seus associados.

Os doze produtores $(86,66 \%)$ que diversificam a produção apontaram como atividades secundárias a produção de batata, milho, feijão, cenoura, beterraba, mandioca, ovos, leite, queijo, nata, requeijão, pipoca, cebola, frutas cítricas, fumo, verduras, temperos, morango, arroz, criação de frangos, piscicultura, apicultura, vitivinicultura, bovinocultura, panificação, costura e tear. Salientase que os agricultores têm uma média de cinco atividades secundárias na produção. Existindo, mesmo assim, produtores com índices maiores de diversificação, chegando a doze atividades secundárias. Tais atividades representam, em média, $40 \%$ da renda agropecuária anual da família.

É visível, também, a importância do Projeto Esperança/Cooesperança para a subsistência familiar, pois este viabiliza a comercialização direta dos produtos, por meio das feiras e dos terminais de comércio, sendo que 53\% dos agricultores familiares associados comercializam mais de $75 \%$ da sua produção via projeto. Destes, $75 \%$ comercializam $100 \%$ da sua produção por meio do Projeto Esperança/Cooesperança. Somando-se a isso, destaca-se que 13,33\% dos produtores precisam adquirir em torno de $40 \%$ a mais de produtos para a comercialização, o que sinaliza que o

Revista de Gestão Social e Ambiental - RGSA, São Paulo, v. 6, n. 3, p. 47-63, set./dez. 2012. 
projeto também está gerando oportunidades para produtores parceiros de associados. Os demais produtores $(86,66 \%)$ têm a produção própria suficiente para a comercialização nas feiras e terminais de comércio. Isto indica a grande influência do Projeto na comercialização dos produtos dos agricultores.

Outro ponto perceptível é a fidelização dos agricultores com o projeto, mais de $73 \%$ participam da Cooperativa há mais de dez anos e $27 \%$ participam a menos de oito anos, representando uma média de dez anos e meio de participação no Projeto.

Este Projeto está alicerçado em valores de cunho coletivo. Para avaliar a interiorização por parte dos produtores rurais sobre este aspecto, foi questionado se o interesse em participar do projeto referese mais a questões de cunho individual ou coletivo. Desta forma, observou-se que $80 \%$ dos pequenos agricultores envolvidos percebem o projeto como coletivo e $20 \%$ não tem essa percepção, buscando apenas sua satisfação individual ou familiar.

Além disso, o Projeto Esperança/Cooesperança insere os agricultores cooperados em uma cadeia de trabalhos relacionada a estudo e formação, proporcionando, por meio de reuniões e cursos, o acesso a informações e atualizações sobre as práticas utilizadas nos processos de produção. Também mostra aos cooperados a viabilidade de se produzir ecologicamente, preocupando-se com a agricultura sustentável, sem prejudicar o meio ambiente e os seres humanos.

Os agricultores destacam ainda as relações interpessoais, tendo em vista que as relações humanas são fundamentais, pois, todos estão interligados: produtores, consumidores, colaboradores e a própria comunidade. O convívio coletivo garante a saúde do grupo e, ao mesmo tempo, o enriquece com a partilha de experiências.

O Projeto Esperança/Cooesperança, como mencionado anteriormente, proporciona a comercialização direta dos produtos para os consumidores. Essa é a principal vantagem destacada pelos agricultores, pois é uma oportunidade estratégica que agrega valor ao seu produto proporcionando que os produtores tenham o contato direto com os clientes.

O que se observa é que os produtores agropecuários que praticam a atividade sustentável veem na Cooperativa a garantia da sua renda mensal. Por meio dos pontos de venda fixos têm freguesia garantida. Além disso, passam de empregados para empregadores, contratando pessoas para o trabalho na própria propriedade rural.

Incluindo os produtores cooperados, estes encontram na cooperativa um meio de ampliar seus horizontes e participar de outras associações e cooperativas. Destacam-se 33\% (cinco entrevistados) de agricultores participantes na Cooperativa Central de Desenvolvimento Rural (Coopercedro), Coopinhal Cereais Ltda (Coopinhal), Cooperativa Agrícola Mista de Nova Palma (Camnpal), Cooperativa Agropecuária de Julio de Castilhos (Cotrijuc), Cooperativa de Crédito Rural com Interação Solidária (Cresol), o Restaurante Popular e na Associação São Paulo Apóstolo (Promovita).

\subsection{Indicadores de sustentabilidade}

No que se refere à sustentabilidade econômica, a Tabela 1 mostra que o ISE para a amostra estudada foi de 0,24 , indicando um baixo nível de sustentabilidade econômica.

Também chama atenção a alta variabilidade no indicador de desempenho econômico (IDE) dos produtores, indicando a grande heterogeneidade do grupo pesquisado. $\mathrm{O}$ desvio-padrão supera $\mathrm{o}$ índice médio, mostrando a elevada variabilidade no resultado econômico obtido por estes produtores no período analisado.

Tabela 1 - Índice de sustentabilidade econômica dos produtores associados ao Projeto Esperança/Coopesperança

\begin{tabular}{ll}
\hline Produtor & IDE \\
\hline 1 & 0,08 \\
2 & 0,48 \\
3 & 0,05
\end{tabular}

Revista de Gestão Social e Ambiental - RGSA, São Paulo, v. 6, n. 3, p. 47-63, set./dez. 2012. 


\begin{tabular}{ll}
4 & 0,31 \\
5 & 0,12 \\
6 & 0,21 \\
7 & 1,00 \\
8 & 0,28 \\
9 & 0,16 \\
10 & 0,47 \\
11 & 0,13 \\
12 & 0,00 \\
13 & 0,20 \\
14 & 0,05 \\
15 & 0,07 \\
Média IDE $=$ ISE & $\mathbf{0 , 2 4}$ \\
Desvio-padrão & $\mathbf{0 , 2 6}$ \\
\hline
\end{tabular}

Fonte: Dados da pesquisa

A Tabela 2 apresenta os resultados para o índice de sustentabilidade social, em termos de valores absolutos e padronizados.

Tabela 2 - Índice de sustentabilidade social dos produtores associados ao Projeto Esperança/Coopesperança

\begin{tabular}{llll}
\hline & ISS & & \\
Produtor & Valor Absoluto & \% do valor máximo & Padronizado \\
\hline 1 & 6,738 & 87,05 & 0,58 \\
2 & 5,471 & 70,68 & 0,00 \\
3 & 5,599 & 72,34 & 0,06 \\
4 & 6,471 & 83,60 & 0,45 \\
5 & 7,671 & 99,11 & 1,00 \\
6 & 7,031 & 90,84 & 0,71 \\
7 & 7,031 & 90,84 & 0,71 \\
8 & 6,931 & 89,55 & 0,66 \\
9 & 6,438 & 83,18 & 0,44 \\
10 & 7,538 & 97,39 & 0,94 \\
11 & 7,131 & 92,13 & 0,75 \\
12 & 7,371 & 95,23 & 0,86 \\
13 & 6,269 & 80,99 & 0,36 \\
14 & 7,031 & 90,84 & 0,71 \\
15 & 6,471 & 83,60 & 0,45 \\
Média & $\mathbf{6 , 7 4 6}$ & $\mathbf{8 7 , 1 6}$ & $\mathbf{0 , 5 8}$ \\
Desvio-padrão & $\mathbf{0 , 6 3 9}$ & & $\mathbf{0 , 2 9}$ \\
\hline
\end{tabular}

Fonte: Dados da pesquisa

O ISS absoluto médio do grupo de produtores foi de 6,746, representando um desempenho de, aproximadamente, $87 \%$ do valor máximo de sustentabilidade social possível para os escores estabelecidos (ISS máximo $=7,74$ ).

O ISS padronizado no intervalo 0 a 1 foi de 0,58 , indicando um nível médio de sustentabilidade social dos produtores pesquisados. Questões relacionadas ao saneamento foram as principais responsáveis pelo desempenho mediano, já que a grande maioria dos produtores estudados possui esgoto do tipo fossa rudimentar e não possui filtro de água, além do abastecimento de água se dar por meio de poço. As questões relacionadas ao aspecto educacional contribuíram positivamente para a formação do índice de sustentabilidade social, visto que a grande maioria dos filhos dos produtores estuda e $100 \%$ deles são alfabetizados.

$\mathrm{O}$ melhor desempenho dos produtores no que se refere à sustentabilidade foi no aspecto ambiental, conforme ilustrado na Tabela 3. 
Tabela 3 - Índice de sustentabilidade ambiental dos produtores associados ao Projeto Esperança/Coopesperança

\begin{tabular}{lll}
\hline Produtor & ISA & \\
\hline 1 & Médio & Padronizado \\
2 & 0,83 & 0,67 \\
3 & 0,67 & 0,17 \\
4 & 0,78 & 0,50 \\
5 & 0,78 & 0,50 \\
6 & 0,89 & 0,83 \\
7 & 0,94 & 1,00 \\
8 & 0,72 & 0,33 \\
9 & 0,94 & 1,00 \\
10 & 0,83 & 0,67 \\
11 & 0,72 & 0,33 \\
12 & 0,89 & 0,83 \\
13 & 0,89 & 0,83 \\
14 & 0,78 & 0,50 \\
15 & 0,94 & 1,00 \\
Média & 0,61 & 0,00 \\
Desvio-padrão & $\mathbf{0 , 8 1}$ & $\mathbf{0 , 6 1}$ \\
\hline
\end{tabular}

Fonte: Dados da pesquisa

O índice de sustentabilidade ambiental médio obtido foi 0,81, com desvio-padrão de 0,10 , indicando baixa variabilidade no conjunto de produtores no que se refere ao desempenho no aspecto ambiental. O ISA padronizado foi de 0,61, indicando uma sustentabilidade de nível médio.

O ISA foi o maior dos três tipos de sustentabilidade analisados, quais sejam, econômica, social e ambiental. Tal fato se deve as boas práticas adotadas pelos produtores no que se refere ao cuidado com o meio ambiente e a adoção de práticas agroecológicas.

Aqui cabe destacar o trabalho feito pelo Projeto Esperança/Cooesperança em se tratando de disseminação das práticas agropecuárias sustentáveis. A Cooperativa possui um técnico (agrônomo) que tem como principal função assessorar os produtores na adoção de práticas ecológicas. Isto pode ser reforçado quando se verifica que diversas práticas ecológicas são adotadas por mais de $90 \%$ dos produtores pesquisados, a exemplo de: utilização de adubação verde e de adubação orgânica, existência de área de preservação de mato nativo, utilização de técnicas de controle natural de pragas e doenças e de práticas de conservação do solo, reaproveitamento de resíduos orgânicos, reciclagem de resíduos ou separação de lixo e não utilização de queimadas.

O índice de sustentabilidade geral dos produtores do Projeto Esperança/Coosperança, dada pela média dos índices de sustentabilidade previamente determinados, foi de 0,48, estando no limiar entre uma baixa e média sustentabilidade, conforme a metodologia de análise da ONU (1994). Este valor pode ser explicado pela baixa sustentabilidade financeira, o que demonstra que os produtores auferem baixos lucros com a atividade agropecuária. No entanto, cabe ressaltar que se verificou a existência de rendas não agrícolas em $66,66 \%$ dos agricultores pesquisados, sendo que estas rendas representam anualmente, em média, cerca de $\mathrm{R} \$ 9.000,00$ por família.

Analisando a renda total da família em relação ao número de membros, tem-se que $40 \%$ das famílias obtêm mais de um salário mínimo por pessoa por mês. Destaca-se também que 33,33\% das famílias auferem mais do que meio salário mínimo por mês por pessoa. Com isto, percebe-se que $73,33 \%$ das famílias pesquisadas recebem, ao menos, meio salário mínimo por pessoa por mês.

É importante lembrar que, neste estudo, não foram avaliados o autoconsumo das famílias, ou seja, não foi mensurado o que é consumido pela família da produção agrícola própria. Acredita-se que este cálculo elevaria significativamente as rendas familiares. Destaca-se, também, que o cálculo da renda levou em consideração o número total de membros da família, não fazendo distinção entre

Revista de Gestão Social e Ambiental - RGSA, São Paulo, v. 6, n. 3, p. 47-63, set./dez. 2012. 
quem trabalha ou não. Se a análise fosse feita considerando a divisão da renda pela força de trabalho, provavelmente a renda por pessoa seria maior.

Vale ressaltar que, após a realização da pesquisa, os resultados foram apresentados para os agricultores pesquisados, bem como para a coordenação do projeto. Este momento teve a finalidade de instrumentalizar a coordenação do projeto, bem como o grupo de produtores para que seja possível a implementação de melhorias, bem como a definição de prioridades de ação.

\section{CONSIDERAÇÕES FINAIS}

Percebeu-se que a sustentabilidade financeira, em comparação com os outros índices, apresentou o resultado mais baixo. Isto pode ser explicado pela pequena escala, muitas vezes em razão da limitação de área ou mão de obra. Por outro lado, destaca-se a satisfação e orgulho dos produtores na atividade, bem como a capacidade de reprodução no sistema. Dos quinze pesquisados, apenas um não pretende continuar na atividade agropecuária.

$\mathrm{O}$ indicador de melhor desempenho foi o de sustentabilidade ambiental, que pode ser analisado a partir da importância do trabalho desenvolvido pelo projeto Esperança/Cooesperança, que tem como um de seus pilares a adoção de práticas agroecológicas e sustentáveis na agropecuária. Os produtores demonstram ter interiorizado esse discurso, pois ao longo das entrevistas fica claro o orgulho de todos ao dizerem que seus produtos têm, de fato, qualidade, sendo que a qualidade, muitas vezes, está relacionada, na percepção dos produtores, com a baixa ou nenhuma utilização de insumos químicos. Isto é reforçado pelo fato de que um dos pesquisados mencionou que só comercializa na feira do projeto os produtos com o mais alto padrão de qualidade, já os produtos inferiores (por exemplo, se foi necessário aplicação de inseticida químico) são comercializados no mercado tradicional de commodities.

A sustentabilidade social ficou com o desempenho intermediário, quando comparada com as demais. Entre os pontos negativos, destacaram-se algumas questões relacionadas ao saneamento, tais como esgoto do tipo fossa rudimentar, baixa presença de filtro de água e abastecimento de água por meio de poço. No entanto, é necessário fazer as devidas ponderações, pelo fato de que as questões mencionadas anteriormente estão presentes na grande maioria do meio rural brasileiro, aliás, inclusive nas cidades. Vale destacar o fato da existência da fossa rudimentar como um avanço em relação ao costumeiro derramamento de esgoto em leitos de água. Por outro lado, chama mais a atenção a questão da escolaridade, ou seja, a total alfabetização dos participantes do projeto e o elevado índice de matrículas dos filhos em escola. Apenas um produtor afirma não ter filhos na escola e, nesse caso, é preciso esclarecer que o filho tem 1,5 anos de idade. Acredita-se que isto também é reflexo do trabalho educativo realizado pelo projeto, que tem como base a inclusão social e a cidadania.

Fica como sugestão uma intensificação de atividades e/ou assistência técnica por parte do projeto para auxiliar na melhoria da sustentabilidade financeira dos produtores, isto poderia se dar a partir de ações voltadas para a agregação de valor e/ou diversificação/inovação da produção. Vale destacar que antes de qualquer tipo de intervenção, recomenda-se, de fato, verificar se os produtores associados sentem necessidade ou desejam se envolver em atividades com a finalidade de incremento de renda. Ressalta-se a importância de se compreender a racionalidade, cultura, historicidade e as expectativas do grupo antes de qualquer tipo de ação.

\section{REFERÊNCIAS}

Aliglieri, L., Aliglieri, L. A., Kruglianskas, I. (2009). Gestão socioambiental: responsabilidade e sustentabilidade do negócio. São Paulo. Atlas.

Almeida, J.(1997). Da ideologia do progresso à idéia de desenvolvimento (rural) sustentável. Revista Educação Agrícola Superior, Brasília, 15(Especial), 51-85.

Revista de Gestão Social e Ambiental - RGSA, São Paulo, v. 6, n. 3, p. 47-63, set./dez. 2012. 
Bastos, V. V. S., Almeida, A. P., Malagodi, E. A., Ferreira, R. P. (2008). Sindicato de Trabalhadores Rurais: um espaço aberto para o debate. Um estudo de caso do Pólo - Sindical da Borborema - Paraíba. In: Encontro da Rede de Estudos Rurais, 3, Campina Grande. Anais... Encontro da Rede de Estudos Rurais, 3.

Benvindo, R. A. F.(2009). Análise comparativa dos instrumentos de regulamentação das políticas de proteção ambiental e de promoção do Ecoturismo: O Caso do Parque Estadual do Jalapão TO. Dissertação (Mestrado em Arquitetura e Urbanismo) - Universidade de Brasília, Brasília.

Bicalho. A. M. de S. M.(1998). Desenvolvimento rural sustentável e geografia agrária. In: Encontro Nacional de Geografia Agrária, 12, 1998.

Bouni, C. (1996). Indicateurs de développement durable: l'enjeu d'organiser une information hétérogène pour préparer une décision multicritère. In: Colloque international sur indicateurs de développement durable, 1996, Abbay de Fontevraud. Annales... [S.l.: s.n.].

Brasil(2006). Censo Agropecuário de 2006. Brasília. Recuperado em 10 dez.2010, de: $<w w w . i b g e . g o v . b r / . . . / a g r o p e c u a r i a / c e n s o a g r o / 2006 / a g r o p e c u a r i o . p d f>$.

Candeias, C. N. B., Macdonald, J. B., Mello Neto, J. F. (2005). Economia solidária e autogestão: ponderações teóricas e achados empíricos. Maceió: Edufal.

Cavalcanti, C. (1998). Sustentabilidade da economia: paradigmas alternativos da realização econômica. In: Cavalcanti, C. (org). Desenvolvimento e natureza: estudo para uma sociedade sustentável. São Paulo: Cortez; Recife, PE: Fundação Joaquim Nabuco.

Cooesperança(2011). Cooperativa Mista dos Pequenos Produtores Rurais e Urbanos Vinculados ao Projeto Esperança. Recuperado em 18 jan. 2011, de: $<$ http://www.esperancacooesperanca.org.br/>.

Depontil, C. M. (2002). Indicadores para avaliação da sustentabilidade em contextos de desenvolvimento rural local. 155 p. Monografia (Especialização) - UFRGS. Programa de PósGraduação em Economia Rural, Porto Alegre.

Desai, N. (2005). Johannesburg and beyond making sustainable development a global reality. In: United Nations. Global Challenge global opportunity: trends in sustainable development. Recuperado em: 15 nov.2010, de: <www.un.org>.

Figueiredo, N. T. C.(2009) Cooperativas sociais: alternativa para inserção. Porto Alegre: Evangraf.

Hoff, D. N. (2008). A construção do desenvolvimento sustentável através faz relações entre as organizações e seus stakeholders: a proposição de uma estrutura analítica. Tese (Doutorado em Agronegócios) - Universidade Federal do Rio Grande do Sul, Porto Alegre.

Icaza, A. M. S., Freitas, M. R. (2006). O projeto Esperança/Cooesperança e a construção da economia solidária no Brasil. Relato de uma experiência. Porto Alegre: Cáritas Brasileira.

Lamge, C. M.(2009). A construção de conhecimentos em espaços de economia popular solidária (o sentido pedagógico do Projeto Esparança/Cooesperança). Ijuí, RS. Pallotti. 
Leff, E. (2004). Saber ambiental: sustentabilidade, racionalidade, complexidade, poder. Petrópolis: Vozes.

Lourenço, M.(2006). Questões técnicas na elaboração de Indicadores de Sustentabilidade. Recuperado em $15 \quad$ abr.2010, de $<$ http://www.unifae.br/publicacoes/pdf/sustentabilidade/marcus_lorenco.pdf>. I Seminário sobre sustentabilidade, 2006.

Marangon, M., Presznhuk, R., Sordi, R.F., Agudelo, L.P.P. (2004). Indicadores de sustentabilidade como instrumento para avaliação de comunidades em crise: aplicação à comunidade de Serra Negra. Revista Educação e Tecnologia - Periódico Técnico Científico dos Programas de PósGraduação em Tecnologia dos Cefets-PR/MG/RJ, 8, set.

Marzall, K., Almeida, J.(2000). Indicadores de sustentabilidade para agroecossistemas - estado da arte, limites e potencialidades de uma nova ferramenta para avaliar o desenvolvimento sustentável. Cadernos de Ciência e Tecnologia, Brasília, 17(1), 41- 59, jan./abr.

Mesquita Filho, J. B. (2006). Análise da sustentabilidade econômica, social e ambiental do cultivo orgânico de hortaliças: o caso dos produtores da Associação para o Desenvolvimento da Agropecuária Orgânica - ADAO. 95 f. Dissertação (Mestrado em Economia Rural) - Universidade Federal do Ceará, Fortaleza.

Mitchell, G. (1996). Problems and fundamentals of sustainable development indicators. Sustainable Development. 4, 1-11.

Moisés, H. N.(1999). O Município-Rede: planejamento, desenvolvimento político e sustentabilidade. In: Fundação Prefeito Faria Lima - Cepam. O município no século XXI: Cenários e Perspectivas. Edição especial. São Paulo, 400p.

Oliveira, A. F. dos S. et al. (2008). A sustentabilidade da agricultura orgânica familiar dos produtores associados à APOI (Associação dos Produtores Orgânicos da Ibiapaba - CE). Congresso da Sociedade Brasileira de Economia, Administração e Sociologia Rural - Sober, 47. Rio Branco, 20-23 de julho.

Pollmann G. da M.(2008). Indicadores de sustentabilidade na prática agroflorestal: um estudo de caso no sitio São Jose, sertão de Taquari, município de Paraty - RJ. Monografia apresentada ao Instituto de Florestas da Universidade Federal Rural do Rio de Janeiro, Seropédica - RJ Junho.

Sachs, I. (1990). Desarrollo sustentable, bio-industrialización descentralizada y nuevas configuraciones rural-urbanas. Los casos de India y Brasil. Pensamiento Iberoamericano, 46, 235256.

Souza, F. das C. S. (2004). Repensando a agricultura: o enfoque da sustentabilidade como padrão alternativo a agricultura moderna. Holos, (20), outubro.

Recebido em: 16/08/2011

Publicado em 27/12/2012

Revista de Gestão Social e Ambiental - RGSA, São Paulo, v. 6, n. 3, p. 47-63, set./dez. 2012. 